\title{
HIV/AIDS-Related Stigma and Discrimination in Workplaces in Tanzania
}

\author{
Telemu Kassile ${ }^{1 *}$, Honest Anicetus ${ }^{2}$, Raphael Kukula ${ }^{3}$ \\ ${ }^{1}$ Faculty of Science, Sokoine University of Agriculture, Morogoro, Tanzania \\ ${ }^{2}$ Directorate of Preventive Services, Ministry of Health and Social Welfare, Dar es Salaam, Tanzania \\ ${ }^{3}$ Independent Consultant (Retired), Occupational Health and Safety, Dar es Salaam, Tanzania
}

\begin{abstract}
Background: Stigma and discrimination against people living with and affected by HIV/AIDS undermines the effectiveness of national efforts to prevent and control the HIV epidemic. In the context of Tanzania, evidence on the incidence of HIV/AIDS-related stigma and discrimination from the perspective of the employees and employers is limited. Objective: To provide an assessment of the pervasiveness of HIV/AIDS-related stigma and discrimination in the workplace in Tanzania. Methods: A cross-sectional study, which employed both qualitative and quantitative techniques, was carried out. Some 181 employees from 23 workplaces participated in the study. Results: About $13 \%$ of the respondents reported existence of some forms of discrimination while about $16 \%$ of the respondents divulged existence of complaints on stigma for HIV/AIDS affected/infected employees in their workplaces. Stigma-related complaints varied between cities, public or private, nature of activity of workplace, and whether the employee had a member of the family who was living with HIV/AIDS ( $p<0.1)$. Conclusion: Effective strategies to end HIV/AIDS-related stigma and discrimination in the workplace should consider the context in which the strategies are to be implemented. HIV/AIDS-related education and availability of health and social supports to HIV/AIDS affected/infected employees could help lower self-stigma and discrimination among affected/infected employees in the workplaces.
\end{abstract}

Key words: HIV/AIDS, workplace, stigma, discrimination, employees, employers, mainland Tanzania

\section{Introduction}

People living with and affected by HIV continue to face stigma and discrimination in many countries across the globe (Joint United Nations Programme on HIV/ AIDS [UNAIDS], 2012). Evidence shows that people living with HIV/AIDS (PLWHA) are more likely to be discriminated against than people with most other health conditions (Deacon \& Boulle, 2006). Such exclusion has a significant impact on societies in which PLWHA live (Turhan, Inandi, \& Inandi, 2006). Stigma and discrimination against PLWHA undermines the efficiency of national efforts to prevent and control the epidemic as noted in many papers (Bharat, 2011; Genberg, Kawichai, Chingono, Sendah, Chariyalertsak, Konda, \& Celentano, 2008; Lau \& Tsui, 2007; Maluwa, Aggleton, \& Parker, 2002). Gari, Doig-Acuña, Smail, Malungo, MartinHilber, \& Merten (2013) reviewed the literature on access to HIV/AIDS treatment in both low and high income countries, showing that stigma was among the barriers to HIV testing in both countries. Musheke, Ntalasha, Gari, Mckenzie, Bond, Martin-Hilber, \& Merten (2013) provided a systematic review of the evidence on factors that influence and hinder uptake of HIV testing, focusing on sub-Saharan Africa (SSA). The authors also

*Corresponding author:telemuk@yahoo.com showed that HIV-related stigma is among the factors that undermine efforts to prevent and control HIV/AIDS and mitigate the impacts of the epidemic in SSA. This is largely because stigma hinders uptake of HIV testing, a critical requirement for access to HIV treatment. In a study conducted in an urban clinic in Kampala, Uganda, authors showed that HIV status disclosure increase support, behavioural change and, HIV prevention in the long term (Atuyambe, Ssegujja, Ssali, Tumwine, Nekesa, Nannungi, Ryan \& Wagner, 2014). The major reasons for termination of employment among HIV infected people were psychological one, not physical or symptoms-associated conditions (Vitry-Henry, Pénalba, Beguinot, \& Deschamps, 1999). Olalekan, Akintunde \& Olatunji (2014) examined stigma and discrimination against PLWHA in Lagos Nigeria. The authors found that PLWHA were depressed because of episodes of stigma and discrimination against their personality in public, family, healthcare and workplace settings. In the review of the literature on HIV-related stigma and discrimination, it was revealed that HIV-related stigma and discrimination is still prevalent across the world, and that governments recognize how this impacts HIV prevention, treatment, care and support (MacQuarrie, Eckhaus \& Nyblade, 2009). Nonetheless, the reduction 
of stigma and discrimination has not been given due attention and resources in national AIDS control programmes to yield a marked impact.

Statistics from the 2011-12 Tanzania HIV/AIDS and Malaria Indicator Survey (THMIS, 1012) show that HIV prevalence among individuals in the age group 1549 years was $5.3 \%$ and varied between men $(3.8 \%)$ and women $(6.2 \%)$. Furthermore, HIV prevalence was higher in urban areas $(7.2 \%)$ than in rural areas $(4.3 \%)$.

In Tanzania, stigma is recognized as one of the major challenges in the prevention and control of the HIV/ AIDS epidemic. This recognition is manifested in the National Policy on HIV/AIDS, which acknowledges that in order to fight against the epidemic; stigma must be prevented consistently by all sectors and at all levels. HIV/AIDS information, education, and communication (IEC) focusing on behaviour and attitudes of workers and employers is deemed an integral part of HIV/AIDS intervention in the workplace settings (United Republic of Tanzania [URT], 2001). Nevertheless, there is limited evidence of perception of employees and employers regarding HIV/AIDS-related stigma and discrimination in the workplace.

This paper provides an assessment of the pervasiveness of HIV/AIDS-related stigma and discrimination in the workplace in mainland Tanzania. The prime goal is to garner evidence that provides an overview of the impact of HIV/AIDS intervention in the workplace environment.

\section{Methods}

\section{Study design}

The data in this paper was based on a cross-sectional research study, which was designed to collect information to assess: (i) provision of health and social support services to HIV/AIDS affected/infected employees by employers, and (ii) existence of stigma and discriminatory working environments for HIV/AIDS affected/infected employees in workplaces in cities in Tanzania. This paper focuses on stigma and discrimination issues.

The study employed both qualitative and quantitative methods and involved a survey of workplaces in Arusha, Dar es Salaam, and Tanga cities. Selection of workplaces for the study was done largely based on the main activity of the workplace. In this respect, workplaces, which by nature of activity had stringent access restriction, were considered ineligible for the study. In total, 23 workplaces from various sectors of activity and from the three study areas were studied.
The primary population of focus in the study were affected/infected employees in the selected workplaces. However, casual labourers and those who were employed on part-time basis were excluded. This restriction was made primarily to ensure that the target respondents constituted a homogeneous population with respect to the issues, which were under investigation in the study. An affected/infected employee was defined as an employee either living with HIV/AIDS or having a member of the family or a close relative living with HIV / AIDS or both. At each workplace, the study selected between 4-11 workers to conduct interviews with. Simple random sampling was used to achieve selection of required employees from each workplace to constitute the overall sample for the study. Besides employees, workplace managers (here referred to as employers) were also interviewed on various aspects of interest in the study. One employer from each workplace participated in the study.

The data were collected through face-to-face interviews using structured questionnaires consisting mostly of closed-end items. The questionnaires were designed in English but translated into Kiswahili (the language, which is widely spoken in Tanzania) in order to facilitate the interviews. The final versions of the questionnaires were pre-tested in order to check their suitability in terms of wording of questions, response categories, and sequence of questions.

Other than the questionnaires, focus group discussions (FGDs) of 4-10 people not involved in the face-to-face interviews were conducted with a view to gaining more insights into specific issues in the study. One FGD was conducted at each workplace.

Data collection took place for about two weeks in March 2006 and was undertaken by a research team, which was comprised of health officials from the occupational health unit of the Ministry of Health and Social Welfare headquarters in Dar es Salaam; regional or district hospitals from each of the three aforesaid study areas; and Muhimbili National Hospital. Others were researchers from the local government and university. Data collection was carried out concurrently in all the study areas.

\section{Ethical consideration}

Ethical clearance was obtained from the Ministry of Health and Social Welfare. After that, permission to conduct the study was obtained from the Municipal Councils in the respective cities and from the management of each of the selected workplaces. Furthermore, written consents were obtained from each respondent or participant prior 
to the interviews or discussions respectively as described in Kassile, Anicetus, Kukula \& Mmbando (2014).

\section{Data analysis}

The analysis of the data involved computations of descriptive statistics and was carried out in the SAS System for Windows version 9.2. The arithmetic mean and standard deviation (SD), and frequency along with corresponding percentage were computed for continuous and discrete variables respectively. The Kruskal-Wallis (KW) rank sum nonparametric equivalent of the one-way analysis of variance technique (Zar, 1984) was employed to check for differences between groups for continuous and non-normally distributed variables. In addition, the chi-square $\left(\chi^{2}\right)$ test of independence of attributes was employed to assess the degree of dependence or independence of variables in the study. Qualitative data were analysed mainly through identification of themes or patterns of phrases or texts recorded. This was achieved through reading and re-reading the texts and identifying coherent categories that summarized and brought meaning to the text. All tests of significance were twosided and considered significant at the 0.05 level.

\section{Results}

\section{Characteristics of workplaces}

Table 1 provides general characteristics of workplaces selected for the study. Of the 23 workplaces selected, 8 (34.8\%) were from Arusha city, 7 (30.4\%) were from Dar es Salaam city, and $8(34.8 \%)$ were from Tanga city. More than 80 percent $(n=19,82.6 \%)$ of the workplaces were privately owned while the remaining four $(17.4 \%)$ were under the government/public. A large number of the workplaces $(n=11,47.8 \%)$ were industries (pharmaceutical, textile, cement, and foods and beverages), 4 (17.4\%) were health facilities, $3(13.0 \%)$ were farms, $2(8.7 \%)$ were municipal councils, 2 (8.7\%) were construction companies, and one (4.3\%) workplace was a hotel. Eleven $(47.8 \%)$ workplaces had employees ranging from 12-90 employees, 8 (34.8\%) had between 91-412 employees, and 4 (17.4\%) had over 412 employees.

In total, 181 employees of whom 57 (31.5\%) were from Arusha city, 58 (32.0\%) from Dar es Salaam city, and more than one-third $(n=66,36.5 \%)$ from Tanga city participated in the study. The mean (SD) number of employees selected to take part in the study from the total workplaces was 7.9 (2.0) people. More than two-thirds $(n=16,69.6 \%)$ of the workplaces had at least 8 employees who were selected to participate in the study while the remaining $30.4 \%(n=7)$ had less than 8 employees. The majority of the workplaces $(n=11,47.8 \%)$ had between 8-9 employees, $30.4(n=7)$ had between 4-7 employees, and $21.7 \%(n=5)$ had between 10-11 employees.

More than one-third $(n=8,34.8 \%)$ of the workplaces had HIV/AIDS-related information, education and communication (IEC) materials and their availability was independent of the study areas/cities $\left(\chi^{2}=0.171\right.$, $p=0.918): n=3,37.5 \% ; n=2,28.6 \%$; and $n=3,37.5 \%$ of the workplaces in Arusha, Dar es Salaam, and Tanga cities respectively had IEC materials. There was a statistical significant dependence between availability of IEC materials and ownership of the workplace $\left(\chi^{2}\right.$ $=9.079, p=0.003)$. Only about $4(21 \%)$ of the 19 privately owned workplaces had IEC materials compared to all $(n=4,100.0 \%)$ public workplaces in the study.

Twenty (about $87 \%$ ) of the workplaces had adopted some strategies to prevent HIV infections in the workplace while the remaining three $(13 \%)$ of the workplaces had not adopted any prevention measures. Of the total employers who had adopted some HIV/AIDS prevention strategies in their workplaces, 17 (85.0\%) reported that they established HIV/AIDS education committees while the remaining three $(15.0 \%)$ reported that they provided condoms. All the three workplaces $(13.0 \%)$, which reported to have not yet introduced any HIV/AIDS prevention measures, were privately owned. Three-quarters $(n=3,75.0 \%)$ of the public workplaces had HIV/AIDS education committees compared to 14 $(73.7 \%)$ of the privately owned workplaces. Moreover, one-quarter $(n=1,25.0 \%)$ of the public workplaces provided condoms compared to two $(10.5 \%)$ that of private workplaces. However, the association between availability of HIV/AIDS prevention measures and type of ownership (public or private) of workplace was statistically not significant $\left(\chi^{2}=1.163, p=559\right)$. The findings revealed further that three-quarters $(n=6,75.0 \%), 42.9 \%$ $(n=3)$, and $100.0 \%(n=8)$ of the workplaces in Arusha, Dar es Salaam, and Tanga cities respectively had HIV/ AIDS education committees. None of the workplaces in Arusha and Tanga cities provided condoms. Workplaces, which provided condoms, were all from Dar es Salaam city. One-quarter $(n=2,25.0 \%), 14.3 \% \quad(n=1)$ and $0.0 \%$ of the workplaces in Arusha, Dar es Salaam, and Tanga cities respectively had no HIV/AIDS prevention measures in place. There was a significant dependence between availability of HIV prevention measures in the workplace and study area/city $\left(\chi^{2}=10.437, p=0.034\right)$. 
Table1. General characteristics of workplaces

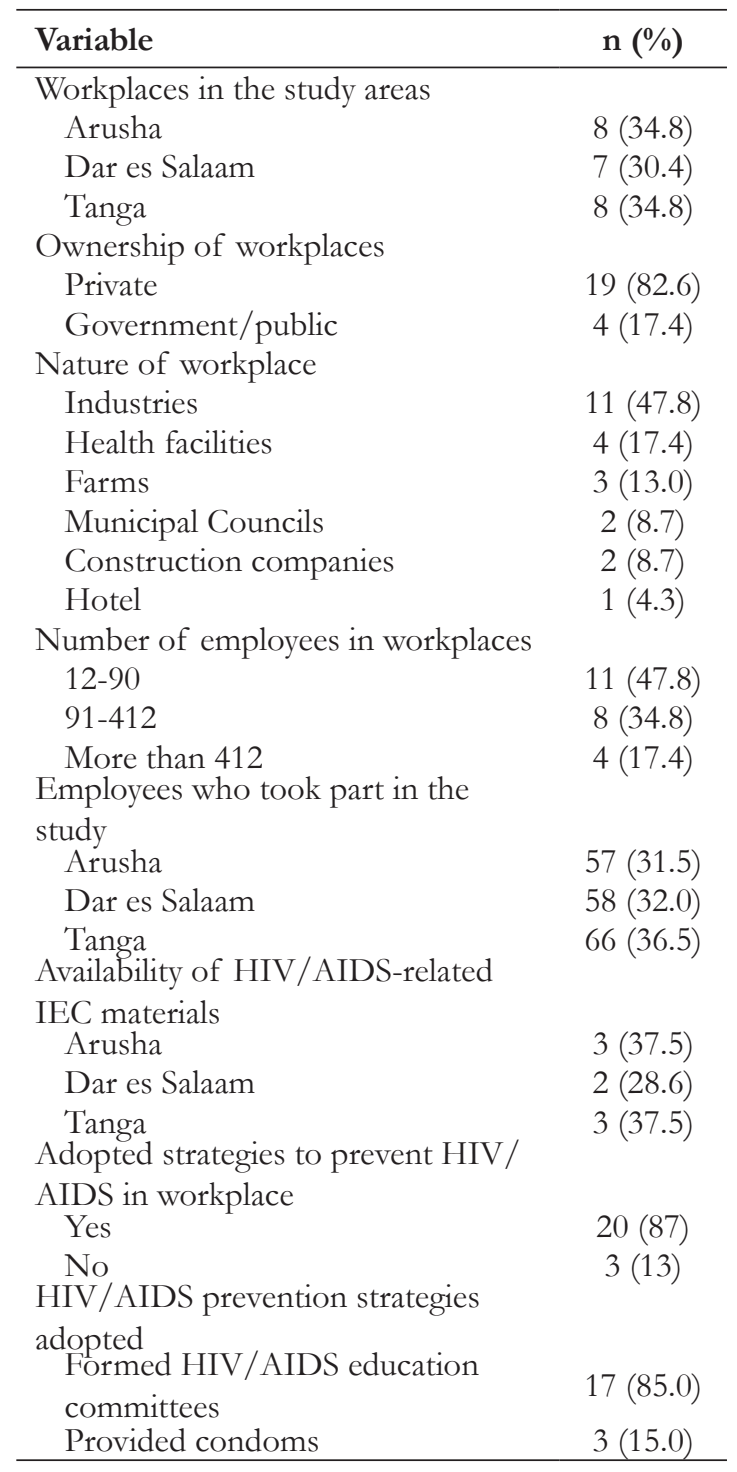

\section{Socio-demographic characteristics of employees}

Table 2 provides socio-demographic characteristics of employees in the study. Of the total employees in the study, $93(51.4 \%)$ were males and $88(48.6 \%)$ were females. Their mean (SD) ages was 36.5 (9.5) years and ranged from 18-68 years. The majority of the respondents were in the age groups 25-34 and 35-44, which represented $39.2 \%(n=71)$ and $34.3 \%(n=62)$ of the total respondents in the study respectively. There was no significant difference in mean ages of employees between cities $(\mathrm{KW}=2.821, p=0.244)$. The mean $(\mathrm{SD})$ number of years since the employees commenced their employment at the workplace was 7.8 (7.5) years and varied between cities $(\mathrm{KW}=16.127, p<0.001)$. Employees in Tanga and Arusha cities were on average (SD), more likely to have spent many years at the workplace compared to their counterparts in Dar es Salaam city: 10.4 (8.3), 7.3 (6.8), 5.5 (6.3) years respectively.
Most of the employees $(n=74,40.9 \%)$ had primary education, more than one-quarter $(n=50,27.6 \%)$ had secondary education, $40(22.1 \%)$ had college/university education, and $12(6.6 \%)$ had technical/vocational training education. A small proportion $(n=5,2.8 \%)$ of the employees had no education at all. Education attainment of employees was significantly associated with study area $\left(\chi^{2}=61.510, p<0.001\right)$. None of the employees in Arusha city and only one (1.7\%) in Dar es Salaam city had no education at all compared to four $(6.1 \%)$ of the employees in Tanga city. Moreover, education attainment was statistically significantly associated with sex of employee $\left(\chi^{2}=15.494, p=0.004\right)$. Female employees were less likely to have attained college/university education compared to their counterpart males: $17.0 \%$ females against $26.9 \%$ males.

Table 2. Socio-demographic characteristics of respondents

\begin{tabular}{ll}
\hline Variable & Value \\
\hline Sex, n $(\%)$ & $93(51.4)$ \\
Male & $88(48.6)$ \\
Female & $36.5(9.5)$ \\
Age, mean (SD) & $7.8(7.5)$ \\
Time (years) at the workplace, mean (SD) & \\
Education, $n$ (\%) & $74(40.9)$ \\
$\quad$ Primary & $50(27.6)$ \\
Secondary & $40(22.1)$ \\
College/University & $12(6.6)$ \\
Technical/vocational training & $5(2.8)$ \\
No education & $129(71.3)$ \\
Marital status, $n$ (\%) & $52(28.7)$ \\
Married & $144(79.6)$ \\
Single & $37(20.4)$ \\
Ever had a child & \\
Yes & \\
No & $43(24 \%)$ \\
Respondent had a member of the family & $138(76.0)$ \\
who was living with HIV/AIDS, n $(\%)$ & $16(28.1)$ \\
Yes & $16(27.6)$ \\
No & $11(16.7)$ \\
Arusha &
\end{tabular}

The majority of the employees $(n=129,71.3 \%)$ were married and more than three-quarters $(n=144,79.6 \%)$ had ever had a child. Employees' marital status was independent of study area $\left(\chi^{2}=8.150, \quad p=0.419\right)$. Likewise, whether or not the respondent ever had a child was not statistically dependent on study area $\left(\chi^{2}=3.002\right.$, $p=0.223$ ). Nevertheless, 3 (about $2 \%$ ) and $5(3 \%)$ of the total employees were widowed and divorced, and mostly in Dar es Salaam $(n=2,3.4 \%$ widowed and $n=3,5.4 \%$ divorced). Moreover, relative to Arusha and Dar es Salaam cities, respondents in Tanga city were more likely 
to report ever having a child: $46(80.7 \%), 42(72.4 \%)$, and $56(84.8 \%)$ respectively.

About $24 \%(n=43)$ of the employees reported to have a member of the family who was living with HIV/AIDS at the time the study was conducted. Employees' disclosure of having a member of the family who was living with HIV/AIDS at the time of the study was not significantly dependent on study area $\left(\chi^{2}=2.887, p=0.236\right)$. However, respondents in Arusha $(n=16,28.1 \%)$ and Dar es Salaam $(n=16,27.6 \%)$ cities were more likely to disclose as having a family member who was living with HIV/AIDS than respondents in Tanga city $(n=11,16.7 \%)$ were.

\section{Episodes of HIV/AIDS-related discrimination in the workplace}

Of the total employees in the study, $23(12.7 \%)$ reported existence of some forms of discrimination in their workplaces. Table 3 presents reports of incidence of discrimination by characteristics of employees and workplaces. As the table shows, reporting of presence of different forms of discrimination was significantly dependent $(p<0.05)$ on employees' marital status, having at least one member of the family who was living with HIV/AIDS, and time (years) since respondent commenced employment at the workplace. Specifically, respondents who were divorced, those with a member of the family living with HIV/AIDS, those who had worked at the workplace for at least 5 years were more likely to report existence of various forms of discrimination than other categories.

Reporting of existence of various forms of discrimination in the workplaces was independent of all other employee or workplace characteristics $(p>0.1)$. Nevertheless, female employees were more likely to report presence of forms of discrimination in the workplace than their counterpart males. Moreover, employees with college/ university education, those aged between 35-44 years, from workplaces where the employer ever talked about HIV/AIDS matters, those who were working in farms, from public owned workplaces, and from Tanga city were more likely to report presence of different forms of discrimination in the workplace. The findings showed also that respondents who reported existence of various forms of discrimination in their workplaces were from $60.9 \%(n=14)$ different workplaces.

Farms, health facilities, and hotel represented the first three highest percentages in terms of reporting of discrimination (results not included in Table 3). These accounted for $20.8,18.5$, and $14.3 \%$ respectively. Others were industry $(11.0 \%)$ and municipal councils $(10.0 \%)$.
None of the respondents in the construction reported existence of discrimination. Only four workplaces in the study had at least one-quarter $(25 \%)$ of their employees reporting existence of various forms of discriminations. However, none of the four workplaces, which had the highest frequencies, had half of the employees reporting existence of discrimination in the workplace.

Three major forms of discrimination were reported namely, reduced opportunities for further training $(n=8$, $34.8 \%$ ), not eating at the same table and working in the same office ( $n=8,34.8 \%)$, and gossiping or "kuteta" Kiswahili translation $(n=7,30.4 \%)$. The majority of the employees $(n=127,70.2 \%)$ in the study reported that their employers had never talked about discrimination against HIV/ AIDS affected/infected employees in their workplaces. Only $54(29.8 \%)$ of the total employees reported that their employers ever talked about discrimination in their workplaces. Employees in the public workplaces $(n=25$, $73.5 \%$ ) were more likely to report that their employers talked with them about discrimination of HIV/AIDS affected/infected employees than their counterparts in the private workplaces $(n=29,19.7 \%)$. There was a highly significant statistical association between the two attributes $\left(\chi^{2}=38.183, p=0.000\right)$. Moreover, male employees $(n=24,25.8 \%)$ were equally likely as female employees $(n=30,34.1 \%)$ to discuss with their employers matters related to discrimination in their workplaces $\left(\chi^{2}=1.482, p=0.223\right)$. Employees in Arusha city $(n=20$, $35.1 \%)$ were a little more likely to discuss with their employers matters related to discrimination than their counterparts in Dar es Salaam $(n=19,32.8 \%)$ or Tanga $(n=15,22.7 \%)$ cities. However, there was not enough evidence to suggest existence of dependence of the two attributes $\left(\chi^{2}=2.581, p=0.275\right)$.

On the question of whether or not the employers ever received complaints/conflicts from HIV/AIDS affected/infected employees, the findings showed that employers in almost all workplaces $(n=22,95.7 \%)$ reported not to have ever received any complaints. The results showed further that in the only one $(4.3 \%)$ workplace where complaints from HIV/AIDS affected/ infected employees were reported, the results revealed that the source of the complaints was discrimination against them (affected/infected employees).

Employees were also asked what they thought should be done in order to end HIV/AIDS-related discrimination in the workplace. The findings showed that about twothirds $(n=15,65.2 \%)$ of those who reported existence of discrimination in the workplace stated that employees should be given both education on HIV/AIDS-related matters and that those living with and affected by HIV 
need to be provided with health and social supports.

The remaining respondents $(n=8,34.8 \%)$ reported that employees should only be educated on matters related to HIV/AIDS.

Table 3. Episodes of discrimination in the workplace

\begin{tabular}{|c|c|c|c|}
\hline \multirow[b]{2}{*}{ Characteristics } & \multicolumn{2}{|c|}{$\begin{array}{l}\text { If there were any forms of HIV/AIDS- } \\
\text { related discrimination at the workplace }\end{array}$} & \multirow{2}{*}{$\begin{array}{l}\text { Chi-square } \\
\text { (p-value) }\end{array}$} \\
\hline & Yes $(n=23,12.7 \%)$ & No $(n=158,87.3 \%)$ & \\
\hline \multicolumn{4}{|l|}{ Sex, n $(\%)$} \\
\hline Male & $9(9.7)$ & $84(90.3)$ & \multirow{2}{*}{$1.583(0.208)$} \\
\hline Female & $14(15.9)$ & $74(84.1)$ & \\
\hline \multicolumn{4}{|l|}{ Education, n (\%) } \\
\hline No education & $0(0.0)$ & $5(100.0)$ & \multirow{5}{*}{$4.064(0.397)$} \\
\hline Primary education & $11(14.9)$ & $63(85.1)$ & \\
\hline Technical/vocational education & $2(16.7)$ & $10(83.3)$ & \\
\hline Secondary education & $3(6.0)$ & $47(94.0)$ & \\
\hline University/college education & $7(17.5)$ & $33(82.5)$ & \\
\hline \multicolumn{4}{|l|}{ Marital status, $\mathrm{n}(\%)$} \\
\hline Never married & $3(7.0)$ & $40(93.0)$ & \multirow{5}{*}{$\begin{array}{l}11.963^{* *} \\
(0.018)\end{array}$} \\
\hline Married & $17(13.2)$ & $112(86.8)$ & \\
\hline Widowed & $0(0.0)$ & $3(100.0)$ & \\
\hline Divorced & $3(60.0)$ & $2(40.0)$ & \\
\hline Separated & $0(0.0)$ & $1(100.0)$ & \\
\hline \multirow{2}{*}{\multicolumn{4}{|c|}{ Had a member of the family who was }} \\
\hline & & & \\
\hline Yes & $9(20.9)$ & $34(79.1)$ & \multirow{2}{*}{$3.438(0.064)$} \\
\hline No & $14(10.1)$ & $124(89.9)$ & \\
\hline \multicolumn{4}{|l|}{ Age, n (\%) } \\
\hline $18-24$ & $0(0.0)$ & $11(100.0)$ & \multirow{5}{*}{$5.514(0.238)$} \\
\hline $25-34$ & $8(11.3)$ & $63(88.7)$ & \\
\hline $35-44$ & $12(19.4)$ & $50(80.6)$ & \\
\hline $45-54$ & $3(10.3)$ & $26(89.7)$ & \\
\hline $55+$ & $0(0.0)$ & $8(100.0)$ & \\
\hline \multicolumn{4}{|l|}{$\begin{array}{l}\text { Time (years) since employee began job } \\
\text { at the workplace, } \mathrm{n}(\%)\end{array}$} \\
\hline $0-4$ & $5(6.0)$ & $78(94.0)$ & \multirow{2}{*}{$\begin{array}{l}6.172 * * \\
(0.013)\end{array}$} \\
\hline $5+$ & $18(18.4)$ & $80(81.6)$ & \\
\hline \multirow{2}{*}{\multicolumn{4}{|c|}{$\begin{array}{l}\text { Employer had ever talked about HIV/ } \\
\text { AIDS matters at workplace, } \mathrm{n}(\%)\end{array}$}} \\
\hline & & & \\
\hline Yes & $7(13.0)$ & $47(87.0)$ & \multirow{2}{*}{$0.005(0.946)$} \\
\hline No & $16(12.6)$ & $111(87.4)$ & \\
\hline \multicolumn{4}{|l|}{ Nature of activity of work place, $n(\%)$} \\
\hline Health facility & $5(18.5)$ & $22(81.5)$ & \multirow{6}{*}{$4.388(0.495)$} \\
\hline Industry & $10(11.0)$ & $81(89.0)$ & \\
\hline Farm & $5(20.8)$ & $19(79.2)$ & \\
\hline Municipal council & $2(10.0)$ & $18(90.0)$ & \\
\hline Construction & $0(0.0)$ & $12(100.0)$ & \\
\hline Hotel & $1(14.3)$ & $6(85.7)$ & \\
\hline \multicolumn{4}{|l|}{ Ownership of workplace, $\mathrm{n}(\%)$} \\
\hline Public & $6(17.6)$ & $28(82.4)$ & \multirow{2}{*}{$0.921(0.337)$} \\
\hline Private & 17 (11.6) & $130(88.4)$ & \\
\hline \multicolumn{4}{|l|}{ Study area, $\mathrm{n}(\%)$} \\
\hline Arusha & $8(14.0)$ & $49(86.0)$ & \multirow{3}{*}{$2.789(0.248)$} \\
\hline Dar es Salaam & $4(6.9)$ & $54(93.1)$ & \\
\hline Tanga & $11(16.7)$ & $55(83.3)$ & \\
\hline
\end{tabular}

*Chi-square significant at 0.1 level; ** significant at 0.05 level 


\section{Episodes of HIV/AIDS-related stigma in the workplace}

Regarding the question of how the respondents regarded workers affected/infected with HIV/AIDS, the study revealed that as many as $167(92.3 \%)$ of the employees in the study reported that they regarded them like any other person. Others said they regarded them in a stigma manner $(n=10,5.5 \%)$ while four $(2.2 \%)$ of the total employees had no opinion. The study revealed further that about $16 \%(n=28)$ of the total respondents divulged existence of complaints on stigma for HIV/ AIDS affected/infected employees in their workplaces (Table 4). Reporting of existence of stigma-related complaints in the workplaces was significantly dependent on several factors. These were whether the respondent had a member of the family who was living with HIV/ AIDS $\left(\chi^{2}=4.410, p=0.036\right)$, main activity of workplace $\left(\chi^{2}=11.309, p=0.046\right)$, and ownership of workplace $\left(\chi^{2}\right.$ $=9.126, p=0.003)$. The remaining factors did not show statisticaly significant results. Overall, respondents who reported existence of complaints were from 13 (56.5\%) of the total workplaces in the study. Stigma-related complaints were more frequent in only three of the total reporting workplaces. Two of the workplaces had more than half $(56.5$ and $75.0 \%)$ of the employees reporting existence of the complaints in their workplaces.

Table 4. Episodes of complaints on stigma from HIV/AIDS affected/infected employees at the workplace

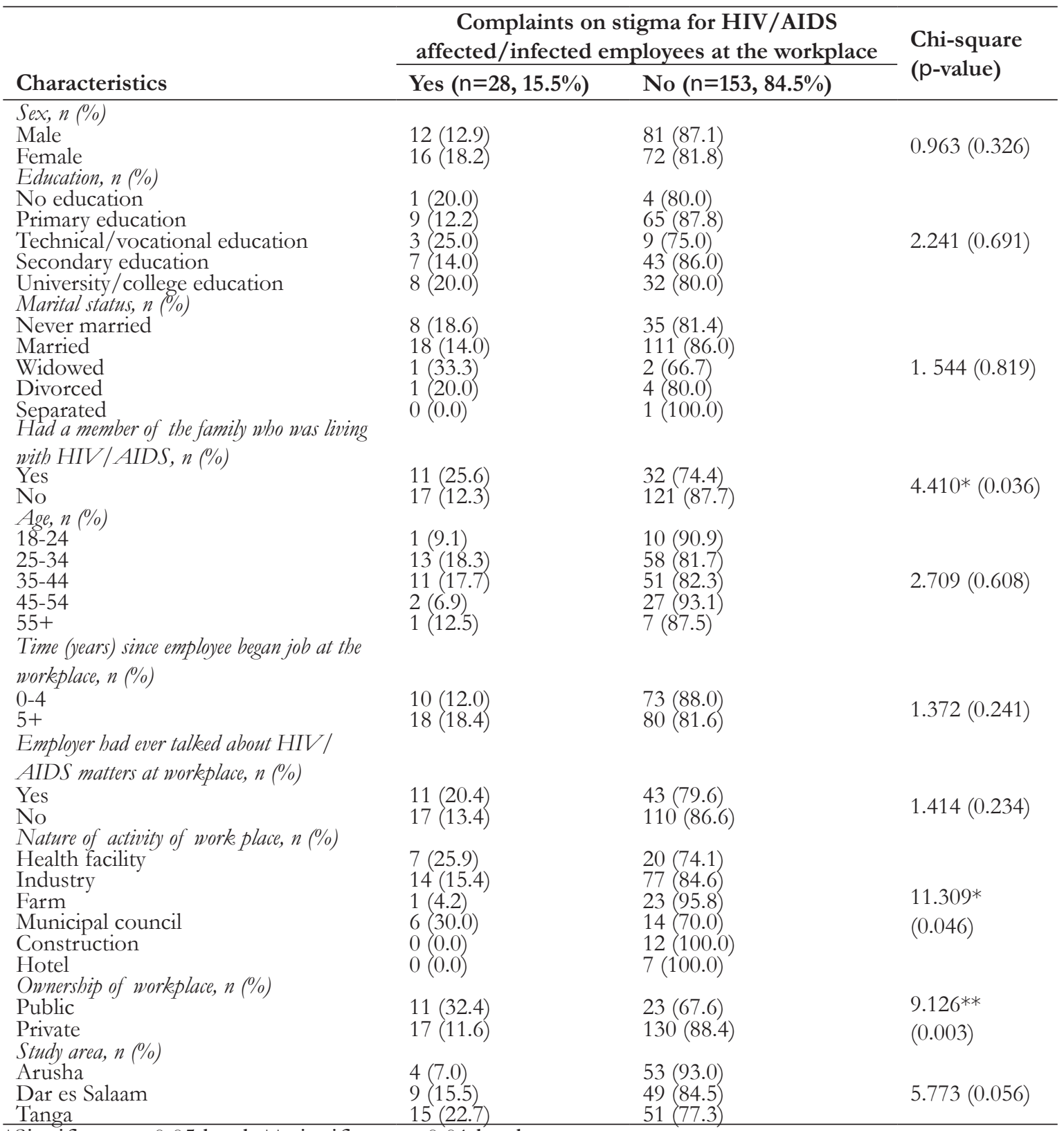

*Significant at 0.05 level; ** significant at 0.01 level 
The study revealed that the most common source of stigma was negative attitudes of co-workers $(n=25,89.3 \%)$. Other sources were negative attitudes of management $(n=1,3.6 \%)$, negative attitudes of clients $(n=1,3.6 \%)$, and negative attitudes of co-workers, management, and customers $(n=1,3.6)$. On the question of what should be done to stop stigma, the findings showed that more than half $(n=15,53.6 \%)$ of the respondents said that workers should be educated while the remaining ( $n=13,46.4 \%$ ) said that workers should be provided with both HIV/ AIDS education and health and social supports.

Findings from the FGDs revealed that in most of the workplaces $(n=20,87.0 \%)$ there was generally no HIV/AIDS-related stigma and discrimination in their workplaces. In the workplaces $(n=3,13 \%)$ where existence of either stigma or discrimination was divulged, the following comments were made:

At one of the three workplaces, participants stated the following: "there is stigma among employees but is caused by lack of HIV/AIDS knowledge". No discrimination was reported at the workplace. A similar comment was made at another workplace: "few employees stigmatize infected employees but no discrimination at all". Participants at another workplace explained that: "there is no stigma and discrimination at our workplace but there is self stigma and self discrimination among the affected/infected employees since they are not willing to cooperate with co-workers"

On the question of what should be done to stop stigma and discrimination, participants in the three workplaces, which reported existence of stigma and discrimination had generally, a similar comment to that made by the employees during face-to-face interviews. That is, "stigma and discrimination will only stop if employers start providing support to the affected/infected employees. If the support is provided no one will fear telling his/ her employer and co-workers about his/ her HIV status and hence people will realize that the HIVI AIDS problem is a normal one and can happen to anybody"

\section{Discussion}

This paper provides an exploration of the incidence of HIV/AIDS-related stigma and discrimination in the workplace in Arusha, Dar es Salaam, and Tanga cities in mainland Tanzania. Nearly equal numbers of employees from each of the three cities participated in the study and showed similar distribution of age, marital status, and disclosing of presence of a member of the family who was living with HIV/AIDS at the time the study was executed. However, employees' distribution in terms of education attainment, gender and duration (years) since individual began working at the workplace varied between the three cities. In the context of mainland Tanzania, regional disparities in educational attainment among groups of individuals such as between males and females are not unexpected. This finding has been observed in several nationally representative populationbased studies conducted in Tanzania. For example, statistics from the 2007-08 Tanzania HIV/AIDS and Malaria Indicator Survey showed that among women aged 15-49, the proportion with at least secondary school education in Arusha, Dar es Salaam, and Tanga cities were 15.2, 22.6, and 5.2\% respectively. (THMIS, 2008). The corresponding figures for men were 21.1, 42.6, and $10.4 \%$ respectively. Though not statistically significant, the finding that employees in Arusha city were more likely to report having an HIV infected family member than those in Dar es Salaam or Tanga cities, is largely consistent with the results in other studies. In the $2007-$ 08 THMIS, respondents were asked a question: if a member of your family got infected with the AIDS virus, would you want it to remain a secret or not? The results showed that among women, the percentages in Arusha, Dar es Salaam, and Tanga cities who said that they would not want to keep secret were 69.6, 43.6, and 38.6 respectively. The corresponding proportions among men were 68.9, 65.6, and 46.0\% (THMIS, 2008).

The finding in this study, that employees in Dar es Salaam city were on average, more likely to be newly recruited than their counterparts in Arusha and Tanga cities is also not unanticipated. This is mainly because relative to other cities or regions in Tanzania, Dar es Salaam is one of the cities with high annual influx rate for people seeking permanent residence. In an Urban Livelihood Assessment survey conducted in Dar es Salaam in the late $1990 \mathrm{~s}$, it was revealed that between $10-16 \%$ of the respondents migrated into the city from other parts of the country within the past five years preceding the survey (International Food Policy Research Institute [IFPRI, 1998). According to Dar es Salaam City Council (DCC), the annual migration rate for permanent residents is estimated to be about $10 \%$ and for transient people, the rate is about 1,000,000 per annum (Dar es Salaam City Council [DCC], 2013). This results in frequent episodes of people newly entering the labour market, the outcome of which is restricted future employment opportunities hence high unemployment rate in the city. According to the 2006 Integrated Labour Force Survey unemployment rate in Dar es Salaam was 31.3\% while in other urban areas it was $16.7 \%$ (National Bureau of Statistics [NBS], 2006). According to the 2002 census counts unemployment rate in Dar es Salaam city was at $46.5 \%$ while in other urban areas was at $25.5 \%$ (DCC, 2013). 
HIV/AIDS intervention in the workplace through information and education, which aims at behaviour and attitudes change among employees and employers, appears not to be widespread across workplaces in the study areas. This is confirmed by the findings in the study in which only slightly above one-third $(34.8 \%)$ of the workplaces had IEC materials. However, IEC materials were uniformly available in the cities but varied between public and private workplaces with frequent reports in the public than in the private workplaces. The study did not explore the types of messages, which the IEC materials contained and the target groups of employees for the materials within the workplace. In this case, therefore, it might be incorrect to deduce that workers in the workplaces across the study areas were exposed to the same level of HIV/AIDS-related knowledge as far as IEC materials in the workplace were concerned. In this study, as already mentioned, education attainment of employees varied between cities. Studies such as that of de Walque (de Walque, 2007) have shown that education decreases the possibility of HIV positive. The positive impact of education on the risk of HIV infection can be achieved through several possible mechanisms. For example, schooling provides an opportunity for people to acquire necessary knowledge about the disease including how the disease is transmitted and how they can protect themselves. Results of the 2004-05 Tanzania Demographic and Health Survey (TDHS) confirm the above assertion in which the percentage of men and women aged 15-49 with comprehensive knowledge about AIDS increased with an increase in the level of education of the respondents in the study ${ }^{1}$ (TDHS, 2005). Among men, the percentage of respondents with at least secondary school education who had comprehensive knowledge about HIV was more than three times higher than that of no education at all respondents: $60.9 \%$ against $18.7 \%$ respectively. Likewise, among females, the corresponding figures were $69.6 \%$ secondary and above education versus $29.5 \%$ no education at all. Because of existence of a strong connection between educational attainment and HIV knowledge, it is persuasive to infer that the study areas were statistically significantly different in terms of responsiveness to the HIV epidemic.

The 2001 National Policy on HIV/AIDS demands each organization to take measures to protect the community

\footnotetext{
${ }^{1}$ According to TDHS (2005), respondents with a comprehensive knowledge about AIDS were those who said that use of condom for every sexual intercourse and having just one uninfected and faithful partner can reduce the chance of getting the AIDS virus. Also included were those who said that a healthy-looking person can have the AIDS virus, and those who reported that AIDS cannot be transmitted by mosquito bites and AIDS cannot be transmitted by supernatural means.
}

from transmission of HIV / AIDS at the workplace (URT, 2013). From the findings of the study, it is evident that by the time the study was implemented in 2006, the Policy's requirement was not put into effect in all workplaces. The findings of the study demonstrated that some $13.0 \%$ of the workplaces in the study had not adopted any HIV/ AIDS prevention measures. This casts a shadow of doubt as to whether the problem of the HIV/AIDS epidemic is equally considered a developmental challenge across workplaces.

HIV/AIDS-related discrimination is prevalent in about $61 \%$ of the workplaces. The various forms of discrimination (reduced privileges for further training, not eating at the same table and working in the same office, and gossiping) that existed in the workplaces were overall, almost equally reported across study areas. However, across all the reporting workplaces, the numbers of employees reporting existence of forms of discrimination were well below $50 \%$. This finding connotes that HIV/AIDS-related discrimination is widespread in the workplaces in the study areas but the episodes of discrimination within the workplaces are infrequent. While over $10 \%$ of the employees reported existence of discrimination in their workplaces, only one $(4.3 \%)$ of the total employers who participated in the study did not divulge existence of HIV/AIDSrelated discrimination. This large discrepancy in responses between employers and employees could be largely attributed to differences in the questions, which the two groups of respondents were asked. The former respondents were asked to state whether they ever received any HIV/AIDS-related complaints from affected/infected employees while the latter group was asked if there were any forms of discrimination for HIV/AIDS affected/infected employees. Not receiving complaints resulting from discrimination of HIV/AIDS affected/infected employees does not necessarily directly translate to non existence of discrimination at the workplace. It could be that workplaces, which had many incidences of discrimination-related complaints differed in terms of characteristics from workplaces, which had fewer incidences of complaints. Indeed, reporting of incidences of forms of discrimination in the study areas varied depending on major socio-demographic and economic characteristics of employees within the workplace.

The findings of the study revealed existence of stigmarelated complaints from HIV/AIDS affected/infected employees in the study areas. This finding is not surprising since some $(6 \%)$ respondents in the study disclosed that they themselves regarded their fellow 
HIV/AIDS affected/infected workmates in a stigma conduct. Lack of HIV/AIDS knowledge among some of the employees appears to be one of the prompts of stigma-related complaints in the study. However, since the study did not collect information on HIV/AIDS knowledge, it remains unclear as to which specific HIV/ AIDS knowledge that some of the employees lacked such that one can associate that limitation with the reported incidences of stigma or discrimination in the workplaces in the study. Moreover, it is not obvious as to why some employees self-stigmatized or self-discriminated as revealed in one of the FGDs. This is because reporting of discrimination or complaint resulting from stigma among HIV/AIDS affected/infected employees was not associated with the respondents' level of education. Worth noting however, is the finding that stigma-related complaints were significantly dependent on whether or not the workplace was a private or public: employees from public workplaces were about three times more likely to report existence of complaints than employees from privately owned workplaces.

The results of the study suggest that employees who had at least one member of the family who was living with HIV were the frequent victims of both stigma and discrimination relative to those who had no member of the family who was living with HIV/AIDS. This could be one of the reasons as to why some respondents in the study reported existence of self-stigma and self-discrimination among the affected/infected employees. In this relation, it is not astounding that most of the respondents were of the opinions that in order to stop stigma and discrimination in the workplaces, HIV/AIDS-related education should be provided. Moreover, supports to the affected/infected employees from employers should also be provided. Differences in the prevalence of HIV/ AIDS-related stigma and discrimination even within areas that seem to be similar in some aspects have been shown to depend on various factors. For example, Mamana, Abler, Parker, Lane, Chirowodza, Ntogwisangu, Srirak, Modiba, Murima \& Fritz (2009) examined the influence of care and treatment resources on HIV-related stigma and discrimination in five high prevalence international sites. The authors (Maman et al., 2009) found that health and socio-economic resources that are designed to ease the impacts of HIV/AIDS were important determining factors of existence of stigma and discrimination in a particular setting. As a result, disparity between settings in these resources explains variability in incidences of stigma and discrimination between areas. In particular, the authors argue that, in areas where there is high access to treatment and care, stigma and discrimination is low.

\section{Conclusion}

This paper provided an assessment of pervasiveness of HIV/AIDS-related stigma and discrimination in the workplace in mainland Tanzania. Reports of existence of stigma and discrimination depended mostly on whether the employee has a member of the family who is living with HIV/AIDS and main activity of the workplace. This study found that relative to employees without a member of the family who is living with HIV/AIDS, employees with at least one HIV-infected family member had a high chance of reporting both stigma and discrimination. On the other hand, stigma and discrimination related practices were reported more frequently in municipal councils and in health facilities than in other areas of work. Moreover, the study found that complaints related to stigma among employees varied between cities suggesting that at the time the study was executed, the benefits of HIV intervention strategies were not uniformly realized across cities. Effective strategies to end HIV/AIDS-related stigma and discrimination in the study areas should consider the context in which the strategies are expected to be implemented. HIV/AIDS-related education and availability of health and social supports to HIV/AIDS affected/infected employees in the workplaces could help lower self-stigma and discrimination among affected/ infected employees in the workplace environment.

\section{Conflict of interests}

The authors declare that they have no conflict of interests

\section{Acknowledgements}

The Ministry of Health and Social Welfare, Tanzania is acknowledged for financing the research study.

\section{Authors' Contribution}

TK: participated in data collection, analysis, interpretation, and writing of the manuscript; HA: participated in data collection, interpretation of results and writing of the introduction section of the manuscript; and RK: participated in the conception and design of the study, supervised data collection, and interpretation of results.

\section{References}

Atuyambe, L. M., Ssegujja, E., Ssali, S., Tumwine, C., Nekesa, N., Nannungi, A., Ryan, G., \& Wagner, G. (2014). HIV/ AIDS status disclosure increases support, behavioural change and, HIV prevention in the long term: a case for an Urban Clinic, Kampala, Uganda. BMC Health Services Research, 276 (14). 
Bharat, S. (2011). A systematic review of HIV/AIDS-related stigma and discrimination in India: Current understanding and future needs. Journal of Social Aspects of HIV/AIDS; 8(3), 139-149. DOI: 10.1080/17290376.2011.9724996.

DCC (2013). Dar es Salaam City Council. Dar es Salaam City Profile [Cited 8 September 2013]; Available from: https://www.google. co.tzsearch?newwindow $=1 \& q=\mathrm{Dar}+\mathrm{es}+$ Salaam + City + profile\&oq $=$ Dar + es + Salaam + City + profile\&gsl $=$ serp.3. $.014 j 0 \mathrm{i} 22 \mathrm{i} 3014.7629 .28867 .0 .31327 .33 .29 \cdot 0.0 .0 .0 .357 .667 .1 \mathrm{j} 2 \mathrm{j}$ 0j1.4.0...0...1c.1.27.serp..29.4.666.rpXMZDB9xCE.

de Walque, D. (2007). How does the impact of an HIV/AIDS information campaign vary with educational attainment? Evidence from rural Uganda. Journal of Development Economics, 84(2), 686-714.

Deacon, H., \& Boulle, A (2006). Factors affecting HIV/AIDSrelated stigma and discrimination by medical professionals. International Journal of Epidemiology, (36), 185-186, DOI: 10.1093/ije/dyl255.

Gari, S., Doig-Acuña, C., Smail, T., Malungo, J. R. S., MartinHilber, A., \& Merten, S. (2013). Access to HIV/AIDS care: a systematic review of socio-cultural determinants in low and high income countries. BMC Health Services Research, 198(13).

Genberg, B. L., Kawichai, S., Chingono, A., Sendah, M., Chariyalertsak, S., Konda, K. A., \& Celentano, D. D. (2008). Assessing HIV/AIDS stigma and discrimination in developing countries. AIDS Behav, (12), 772-780. DOI 10.1007/s10461-007-9340-6

IFPRI (1998). Dar es Salaam Urban Livelihood Challenges, 1998. [Cited 24 September 2013] Available from: http://www.ifpri.org/sites/default/files/publications / daressalaam.pdf.

Kassile, T., Anicetus, H., Kukula, R., \& Mmbando, B. (2014). Health and social support services to HIV/AIDS infected individuals in Tanzania: employees and employers perceptions. BMC Public Health, 630(14).

Lau, J. T. F., \& Tsui, H. Y. (2007). Comparing the magnitude of discriminatory attitudes toward people living with HIV/ AIDS and toward people with mental illness in the Hong Kong general population. Health Education Research, 22(1), 139-152. DOI:10.1093/her/cyl058.

MacQuarrie, K., Eckhaus, T., \& Nyblade, L. (2009). HIVrelated Stigma and Discrimination: A Summary of Recent Literature, 2009. [Cited 8 September 2013] Available from: http:/ / data.unaids.org/Pub/report/2009/20091130_ stigmasummary_en.pdf

Maluwa, M., Aggleton, P., \& Parker, R. (2002). HIV- and AIDS-Related Stigma, Discrimination, and Human Rights: A Critical Overview. Health and Human Rights, 6(1), 1-18.
Mamana, S., Abler, L., Parker, L., Lane, T., Chirowodza, A., Ntogwisangu, J., Srirak, N., Modiba, P., Murima, O., \& Fritz, K. (2009). A comparison of HIV stigma and discrimination in five international sites: The influence of care and treatment resources in high prevalence settings. Social Science \& Medicine, (68), 2271-2278. DOI: 10.1016/j. socscimed.2009.04.002

Musheke, M., Ntalasha, H., Gari, S., Mckenzie, O., Bond, V., Martin-Hilber, A., Merten, S. (2013). A systematic review of qualitative findings on factors enabling and deterring uptake of HIV testing in Sub-Saharan Africa. BMC Public Health, 220(13).

NBS (2006). Integrated Labour Force Survey 2006. United Republic of Tanzania. [Cited 24 September 2013] Available from: http://www.nbs.go.tz/tnada/index.php/ ddibrowser/4/reports.

Olalekan, A. W., Akintunde, A. R., \& Olatunji, M.V. (2014). Perception of societal stigma and discrimination towards people living with HIV/AIDS in Lagos, Nigeria: A qualitative study. Mater Sociomed, 26(3), 191-194.

TDHS (2005). Tanzania Demographic and Health Survey 2004-05. National Bureau of Statistics, Dar es Salaam, Tanzania and ORC Macro, 2005.

THMIS (2008). Tanzania HIV/AIDS and Malaria Indicator Survey 2007-08. Tanzania Commission for AIDS, Zanzibar AIDS Commission, National Bureau of Statistics, Office of the Chief Government Statistician, and Macro International Inc. Dar es Salaam, Tanzania, 2008.

THMIS (2012). Tanzania HIV/AIDS and Malaria Indicator Survey 2011-12. Tanzania Commission for AIDS, Zanzibar AIDS Commission, National Bureau of Statistics, Office of the Chief Government Statistician, and Macro International Inc. Dar es Salaam, Tanzania, 2012.

Turhan, E., Inandi, Y., \& Inandi, T. (2006). Risk perception, knowledge and social distance of Turkish high school students about HIV/AIDS. Journal of Public Health, 28(2), 137-138. DOI:10.1093/pubmed/fdi085.

UNAIDS (2012). UNAIDS report on the global AIDS epidemic 2012. [Cited 2 September 2013] Available from: http://www.unaids.org/en/resources/publications/2012/ name,76121,en.asp.

URT (2001). United Republic of Tanzania Prime Minister's Office. National Policy on HIV/AIDS, 2001. [Cited 5 September 2013]; Available from: http://www.tanzania. go.tz/pdf/hivaidspolicy.pdf.

Vitry-Henry, L., Pénalba, C., Beguinot, I., \& Deschamps, F. (1999). Relationships between work and HIV/AIDS status. Occup. Med. 49(2), 115-116.

Zar, J. H. (1984). Biostatistical Analysis. 2nd Edn., Prentice-Hall, 1984, ISBN-10: 0130779253, pp: 718. 